\title{
Are Higher Education Institutions Positioned To Reap The Dividends Of Open Education Resources? The Case Of Durban University Of Technology
}

A. D. van der Merwe, Durban University of Technology, South Africa

\begin{abstract}
The potential benefits of open education resources (OERs) are well documented in the literature. These include cheaper education, improved equity in respect of educational prospects, greater access to higher education opportunities for non-traditional learners, encouraging new modes of collaborative learning and leveraging public funds by sharing knowledge. So compelling are these advantages that leading universities globally are currently experimenting with new business models calibrated to extract value from educational offerings that, increasingly, will be expected to include free content.

In spite of the obvious merits of OERs, the open education movement faces challenges which are rooted significantly in educators' perceptions of these resources. This descriptive case study sought to examine the attitudes Durban University of Technology (DUT) faculty have towards OERs with the aim of gauging their capacity to be actively involved as developers and users of these materials. The study found that in spite of respondents' recognition of the advantages of OERs and even a degree of superficial employment of these instructional aids, there appears to be no real open education ethos at the institution. Evidence of this includes the relatively low level of sharing of content amongst faculty and the consensus of respondents that there is no institutional support for OER initiatives. The study concludes that for the university to retain its relevance in an evolving educational landscape, it should create a framework that will not only create space for OER projects but should also address the very human need for recognition and acknowledgement that developers of free and open content have.
\end{abstract}

Keywords: Open Education Resources; Open Educational Resources; Open Education; Higher Education

\section{INTRODUCTION}

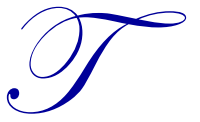

here is growing momentum among higher education institutions to participate in the open education movement (Caswell et al 2008). Surely a significant inspiration for 'opening' up education is the instinct that it is a fundamental human right. Indeed, Article 26 of the Universal Declaration of Human Rights states that each individual has the right to education, and that "technical and professional education shall be made generally available" (Anon., 1948). An important aspect of the ideal of open education is its resource base. Open educational resources (OERs) include learning and research resources that reside in the public domain or have been released under intellectual property license that permits their free use and customisation by others.

South Africa's Green Paper for Post-School Education and Training (DHET, 2012), in pledging to support the production and sharing of OER and advocating the adoption of an open licensing framework by all education stakeholders, recognises the potential benefits of the open education movement. These include cost reductions, expanding participation in higher education by increasing access to non-traditional learners, promoting lifelong learning, bridging the gap between formal and informal learning and leveraging tax revenue by sharing knowledge 
(Hodgkinson-Williams, 2010). Equally well recognised, however, are some of the challenges facing OERs. Thus a lack of broadband and other technical innovations, interoperability issues, a deficiency of resources both to invest in broadband and to cover the cost of developing OER projects, an absence of technical skills, unwillingness to share intellectual property and concerns about the quality of open content all pose potential barriers to the uptake of OERs (Hodgkinson-Williams, 2010).

In spite of the considerable challenges that the open educational movement faces there seems to be growing confidence that this movement is set to reshape the higher education landscape (Carey, 2012). This paper, on a descriptive case study basis, examines the attitudes Durban University of Technology (DUT) instructors have of OERs with a view to assessing their general willingness and capacity to be actively involved as collaborators in the movement, both as developers and users of OERs. The findings reported here may serve as useful indicators of DUT's capacity to re-engineer its business model to offer quality programmes in a competitive higher education market. This is a market that is likely in future to be characterised by uncertainty as new modes of delivering education are trialled. It is possible that DUT's experience may hold lessons for other higher education institutions.

\section{REVIEW OF THE LITERATURE}

Attitudes towards OERs are likely to be conditioned by a number of factors. These include the changing higher education labour market, the anticipated benefits of OERs and the challenges of harnessing these materials on any significant scale. Above all, individuals' experiences of OERs will naturally inform their perceptions of these resources. These considerations are reviewed briefly here.

\section{The Meeting Ground of Economics and Open Education Pedagogy}

The gathering swell of free sharing of content, according to Butcher (2010) signals the decline of industries (notably higher education institutions) that sell educational content. He proposes further that education is not well served by conventional market economics in being subjected to the same rules and incentives as the commercial and retail sectors. The practice of educational institutions being rewarded for competing with each other and withholding their intellectual property from others, he argues, seems antithetical to the notions of building and sharing knowledge which are central to the core functions of public universities.

The economic arena in which education is transacted has certain special characteristics. The first of these is that the commodity of education has both private and public good characteristics. The benefits of education can be enjoyed by many users concurrently as well as sequentially without being diminished. At the same time, it is also possible to withhold education, which makes it at least partly a private good. The market for education is vulnerable to failure since it is a mixed good and this fact explains government interest in it.

Secondly, certain characteristics of knowledge render it a resource whose elements are not scarce in the traditional sense. Thus the more skills and competencies are used, the more they improve (Lundvall, 2003). This suggests that knowledge production is a process of joint production, in which innovation is one kind of output and the learning and skill enhancement that takes place in the process is another. Lundvall's observation that recent models of innovation emphasise knowledge production/innovation as an interactive process in which firms interact with customers, suppliers and knowledge institutions resonates with Casserly's view (2007) of what teaching and learning philosophy should be in the $21^{\text {st }}$ century knowledge-based economy.

Casserly proposes that, to meet the needs of the information-based economy, it is necessary to challenge traditional views of teachers as primarily the dispensers of knowledge. Students, she argues, learn best not as passive recipients but by analyzing, creating, collaborating, and continually assessing their learning much in the style posited by contemporary innovation models. This learning process seems well matched to the essential feature (besides accessibility) of OERs that content is open for modification and change. Thus student learning and creativity are facilitated by the opportunity for content creation. Teachers have the opportunity to adapt OER content for local contexts while openness creates opportunities for groups to collaborate in learning and in the production of modified and/or new content. Casserly speculates that in such an open education environment the nature of teaching may naturally evolve from the traditional imparting of knowledge to coaching, where teachers structure active engagement and moderate collaborative learning processes, rather than only impart knowledge. 


\section{The Changing Higher Education Market}

While open education economics and pedagogy appear to be remoulding the educational landscape, Butcher (2010) highlights two further considerations as a result of open licensing frameworks which are likely to impact on the higher education market. The first is that, since the sale of proprietary content seems destined to become an obsolete model, universities must hope to succeed primarily by accepting that their real potential educational value may lie in their competence to provide effective support to students. Thus does the university offer practical sessions, tutorials, individual counselling sessions and online resources? What is the university's ability to afford intelligent assessment and critical feedback to students on their performance (ultimately leading to some form of accreditation)?

\section{Testing the Waters}

A growing number of leading higher education institutions recognise that the business of higher education is being re-scrambled around the internet which can be used to deliver content at practically zero marginal cost (Brooks, 2012). The race is on to find alternative business models that anticipate the true nature of knowledge as a commodity. Large sums of money are being spent by leading American universities in particular on developing online capacity to experiment with different modes of delivering educational content. In most cases it is not clear whether these ventures will be at least self-sustaining if not profitable (Young, 2012).

\section{The Potential of Open Education}

The growing numbers of open education initiatives, seemingly largely uninhibited by the lack of sustainable business models for the time being, suggest that the potential benefits of open education are unanswerable. According to Geser (2012) these include:

- $\quad$ Higher returns on public funds invested in education through improved cost-effectiveness when reusing resources (e.g. sharing development costs among institutions or professional communities).

- $\quad$ The creation of networks for the production and sharing of educational resources based on a strong emphasis of re-usability.

- $\quad$ Enriching the pool of resources (content and tools) for redesigning curricula and improving teaching and learning practices without the need to worry about copyright issues.

Other possible benefits of OERs include the prospect of leveraging the educational quality of content through quality control, feedback and improvements within content alliances, communities and networks who share content. Furthermore open education may promote lifelong learning and social inclusion through easy access to resources that might otherwise not be accessible.

\section{...And the Reality}

Kanwar, Kodhandaram and Umar (2010) note that in spite of their considerable potential, the promise of open education and OERs has often not translated into concrete and tangible results. Various reasons have been offered for this not least of which are sustainability concerns. Most OERs are sustained by donor funding and if this is withdrawn the project fails. Kanwar et al (2010) cite the example of the discontinuation of Utah State University's Open Courseware Movement which, in spite of its excellence, was aborted in 2009 due to lack of funding. There seems to be a general consensus that, despite rapid growth, the long-term financial sustainability of OERs remains an open question (Geith and Vignare, 2008; Hodgkinson-Williams, 2010).

Further challenges include the general uncertainty regarding the issues of quality assurance and licensing (Yuan et al, 2008; Hodgkinson-Williams, 2010). To these can be added a lack of broadband and other technical innovations, interoperability issues, lack of time to produce shareable materials and the fact that research tends to be privileged over the development of teaching materials. The lack of technical skills, unwillingness to share or give away intellectual property, a reluctance to use resources developed by someone else, and a lack of awareness of copyright issues are further factors that may slow the uptake of OER. Some of these factors are beyond the control 
of faculty while others are attitudinal and are informed by personal characteristics. It is also not unreasonable to assume that the environment in which faculty work is likely to influence their attitudes.

The findings of Elias and Elias (2001) suggest that the attitudes of instructors towards open education may profoundly affect its pedagogic value in terms of producing superior learning relative to traditional 'closed' modes of education. The analysis that follows probes to what extent DUT faculty may be disposed to embracing OERs both as users and developers.

\section{METHOD}

This case study was based on an online survey of DUT faculty across its five campuses, six faculties, its Centre for Excellence in Teaching and Learning, as well as its Business Studies Unit. The questionnaire was administered in the second half of 2011 with a follow up invitation to faculty to participate in the survey about a month after the first invitation. A total of 80 responses were received (52 full and 28 partially completed questionnaires).

\section{The Survey Instrument}

The standardised electronic questionnaire comprised a general section in which some biographical information was elicited and also a section dealing with open educational resources in the classroom. A mix of multiple choice and written response questions were mostly employed in the biographical section. Five-point Likert scale items were generally used in the balance of the questionnaire to examine respondents' attitudes towards open education resources. In total, the survey instrument comprised 24 main items.

\section{Data Validation}

The survey exercise returned 52 complete and 28 incomplete responses. This apparently significant rate of item non-response should be regarded in the context that the survey was designed not to force responses so as to avoid possibly untruthful answers. Given that respondents may not be familiar with open education and OERs it is likely that item non-response, especially in respect of attitudes towards open education resources (the Likert scale items), is an indicator of this uncertainty rather than any bias introduced by the survey instrument.

The incidence of non-response for the Likert scale items ranged from 39\%-50\%. However the rating scale items all proved to have a high internal consistency in terms of gauging respondents' attitudes towards various aspects of open education resources (Cronbach's Alpha > 0.7). In addition Little's MCAR test of the data $(p=0.999)$ suggests that the missing data are randomly distributed across all observations and thus unlikely to be influenced by respondents' characteristics. Accordingly the available data in all the questionnaires was analysed using listwise deletion to exclude cases with missing data.

\section{Population Characteristics}

The population of permanent and contract academic staff at the time of the survey (2011) was 585 and comprised slightly more males (313) than females. The average age of faculty was 46.23 years and the median age 45.63. The average number of years of service was 14.21 and the median years of service was 13.55 . Faculty with doctorates constituted $12 \%$ of the population while $43 \%$ had masters degrees. 


\section{Sample Characteristics}

Table 1 reflects the frequency distribution of responses received from faculty in DUT's various faculties and units. Only the Business Studies Unit offered no responses.

Table 1: Frequency Distribution of Responses

\begin{tabular}{|l|c|}
\hline \multicolumn{1}{|c|}{ Faculty/Unit } & $\%$ \\
\hline Accounting and Informatics & 13.75 \\
\hline Applied Sciences & 6.25 \\
\hline Arts and Design & 11.25 \\
\hline Centre for Excellence in Teaching and Learning (CELT) & 5.00 \\
\hline Engineering and Built Environment & 11.25 \\
\hline Faculty of Health Sciences & 13.75 \\
\hline Faculty of Management Sciences & 16.25 \\
\hline Business Studies Unit & 0 \\
\hline Undisclosed & 22.5 \\
\hline
\end{tabular}

The sample comprised more females (49\%) than males (38\%) while $13 \%$ of respondents did not disclose this information. The average age of respondents was 43.11 years and the median age 42.5 years. The average number of years of service of respondents was 13.37 and the median 10 years. The proportion of the sample that were qualified to doctoral level was $8.75 \%$ while $43.75 \%$ had masters degrees and $16.25 \%$ did not volunteer this information. A comparison of the sample and population characteristics would suggest that the former is reasonably representative of the latter.

\section{ANALYSIS}

\section{Ground Zero}

The attitudes of faculty towards open education/resources should be examined in the context of their circumstances. Thus, the average number of students per class taught by respondents was 58 and each respondent was involved in teaching at least one or more levels ranging from first year through to doctoral level studies. The majority of respondents (79\%) indicated that the students they taught were generally in the lower-to-middle income bracket. This finding squares with the common experience of DUT faculty that their students often do not, maybe cannot afford to, purchase prescribed texts. If, in the experience of faculty, students cannot afford study material then this suggests that they may be responsive to the merits of suitable OERs.

Slightly more than half (57\%) of the respondents confirmed that they do employ open educational content in their teaching approaches and that these resources comprised about $20 \%$ of their instructional materials. The rate of non-response (39\% in respect of this question) suggests that a significant number of respondents may not be clear about usage rights pertaining to some of the materials they employ. If true then this accords with the finding recorded in the literature that OER uptake may be hampered by uncertainty in respect of licensing issues.

Notes (31\%), exercises/quizzes (31\%), tasks/assignments (25\%) and other free online content (29\%) were the most popular materials accessed by faculty. Most respondents $(62 \%)$ rated the quality of these resources as reasonable-to-good (17\% were uncertain, $18 \%$ non-response). In spite of some use of open educational resources, the most popular materials are those produced by faculty (59\%), prescribed texts (39\%) and library sources (36\%), all of which have copyright implications. Only $16 \%$ of respondents reported that they used materials produced by colleagues. Without knowing more about the attitudes of DUT faculty to OERs, it remains an open question as to what this indicates about the ethos and culture of sharing and openness at the institution.

Since the bulk of OERs are distributed and accessed primarily online, the attitudes of faculty towards these materials is likely to be influenced by whether they are comfortable with, and at least reasonably proficient in, using information and communication technologies (ICTs). Respondents were asked to rate their level of comfort with ICTs on a scale of $0-10$ with 0 indicating zero comfort and $10=100 \%$ comfort. The mean level of comfort indicated was 7.8 (median $=8$ ). Respondents were also asked to score their proficiency on the same scale. The proficiency 
scores corresponded closely with the comfort scores $($ mean $=7.6$, median $=8$ ). These results suggest that DUT faculty are sufficiently qualified to at least comfortably and proficiently access the bulk of OERs.

\section{The Attitudes of DUT Faculty to OERS}

The inference that one is tempted to draw at this juncture is that OER use among DUT faculty appears to be reasonably commonplace. However, use of these materials seems to be at a low and fairly unsophisticated (e.g. notes and quizzes) level relative to own and traditional resources employed by instructors. Furthermore, the fact that the rate of sharing of educational resources among colleagues at DUT is quite low (16\%) raises questions about how conducive its academic culture is to open education. Some of these questions could be answered if it were possible to know what benefits instructors expect from employing OERs, what acknowledgement they expect for OERs they may create and what challenges they anticipate in employing and producing such materials.

\section{What Would Motivate Faculty to Use OERs?}

Instructors would most likely gain their initial exposure to OERs by using them. Faculty were asked to rate the importance of some potential benefits of using OERs ( $1=$ very important and $5=$ unimportant $)$.

While the expected benefits listed in Table 2 all appear to be at least important to faculty, their relative percent values are probably more useful in terms of indicating possible broad patterns. Thus developing more suitable and flexible teaching materials (94\%), gaining access to the best possible resources (85\%), reducing costs for students (84\%) and promoting educational research as a publicly open activity (80\%) are the stand-out goals of instructors interested in using open education resources. These findings anticipate the appeal of OERs described by Casserly (2007), namely that instructors have the opportunity to adapt OER content to suit local circumstances. In addition the apparent acceptance by respondents that educational research should be promoted as an open activity resonates with Casserly's suggestion that openness creates opportunities for groups to collaborate in learning and in the production of modified and/or new content in the constructivist pedagogic tradition.

Table 2: The Benefits Faculty Expect from OER Use

\begin{tabular}{|l|c|}
\hline \multicolumn{1}{|c|}{ Expected Benefit } & $\begin{array}{c}\text { Percent Of Respondents Rating The Expected Benefit As } \\
\text { Important-To-Very Important (\%) }\end{array}$ \\
\hline Gain access to the best possible resources & 85.1 \\
\hline Promote educational research as a publicly open activity & 80.4 \\
\hline Reduce costs for students & 84.4 \\
\hline Reducing instructional costs for the university & 74.5 \\
\hline Outreach to students/pupils in disadvantaged communities & 74.4 \\
\hline Contribute to teacher upgrading in disadvantaged schools & 67.4 \\
\hline $\begin{array}{l}\text { Becoming independent of commercial publishers and } \\
\text { vendors }\end{array}$ & 67.5 \\
\hline Developing more suitable and flexible teaching materials & 93.6 \\
\hline Building sustainable teaching partnerships & 68.1 \\
\hline Other & 50 \\
\hline
\end{tabular}

\section{What Would Inspire Faculty to Develop OERs?}

Clearly the sustainability of the open educational movement depends not only on whether resources are being usefully employed but crucially also on individuals taking the time and effort to create and continuously improve these materials. Faculty were asked what would motivate them to develop open educational materials. Their responses were recorded using a 5 -point Likert rating scale ( $1=$ very important, $5=$ unimportant $)$. 
Figure 1 reveals that close to half the respondents $(44 \%)$ indicated that it would be very important to be acknowledged as the creator of the resource by users, while $69 \%$ (44\% very important $+25 \%$ important) felt that it would be at least important to enjoy such recognition. Since an important aspect of open education resources is whether they can be modified/redesigned without copyright encumbrances, respondents were invited to rate how important it is to be acknowledged as the creator of the resource were it to be adapted. Similar proportions stated that it was either very important $(43 \%)$ or at least important $(71 \%)$.

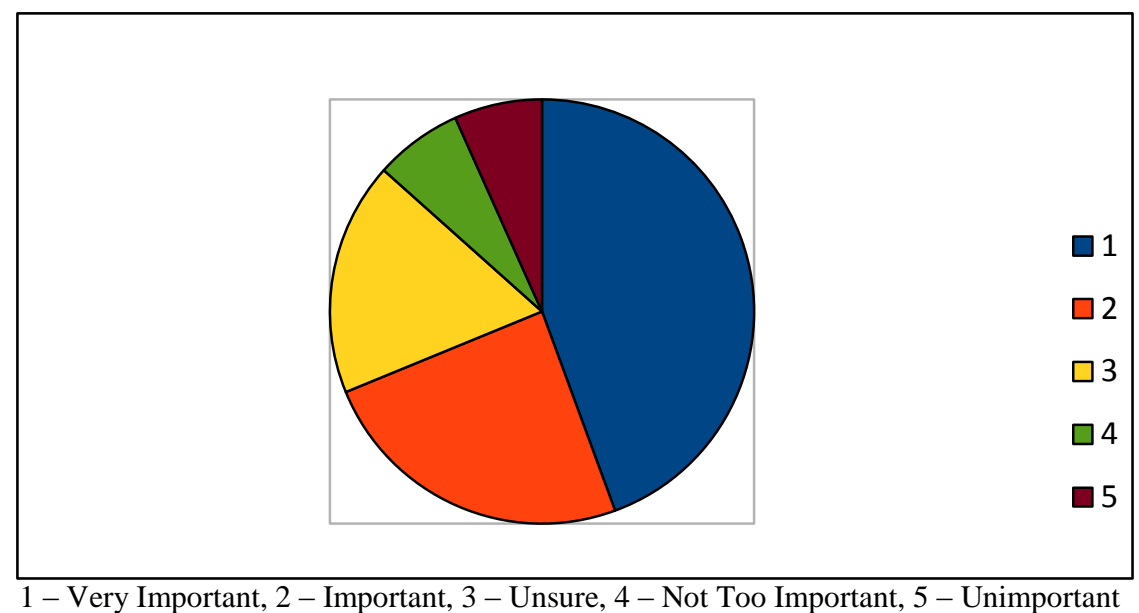

Figure 1: Be Acknowledged as the Creator of the Resource by Users

Faculty also felt strongly about who might use the resources they create, how these materials are used and what adaptations are made to them. Figure 2 reveals that just over half the respondents $(52 \%)$ felt that it was very important to know who uses any resource they may create and 73\% indicated that this knowledge was at least important. Knowledge of how these resources are used once released was very important to $49 \%$ of respondents and $69 \%$ stated that this was at least important to know. A very strong majority $(84 \%)$ indicated that it was at least important to know what modifications are made to any resources they create.

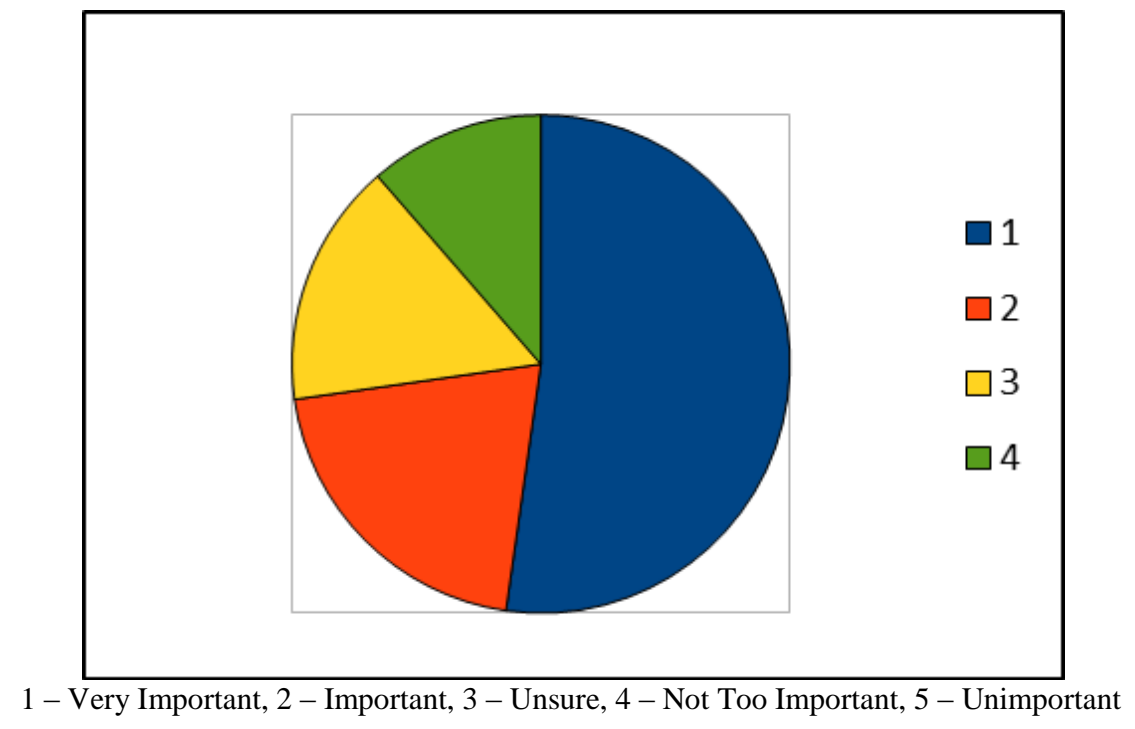

Figure 2: Know Who Uses the Resource 
Respondents were asked how important financial incentives might be in terms of encouraging them to develop open educational materials. Figure 3 shows that only 18\% thought that this was very important although 50\% thought that it was at least important $(18 \%+32 \%)$. An appreciably larger proportion of faculty thought it would be very important $(33 \%)$ or at least important $(58 \%)$ to be personally rewarded by means of promotion, award or other mechanism for the development of OERs. A similar proportion of respondents $(60 \%)$ indicated that it was at least important that their department or school be recompensed for the development and use of any resources they might create.

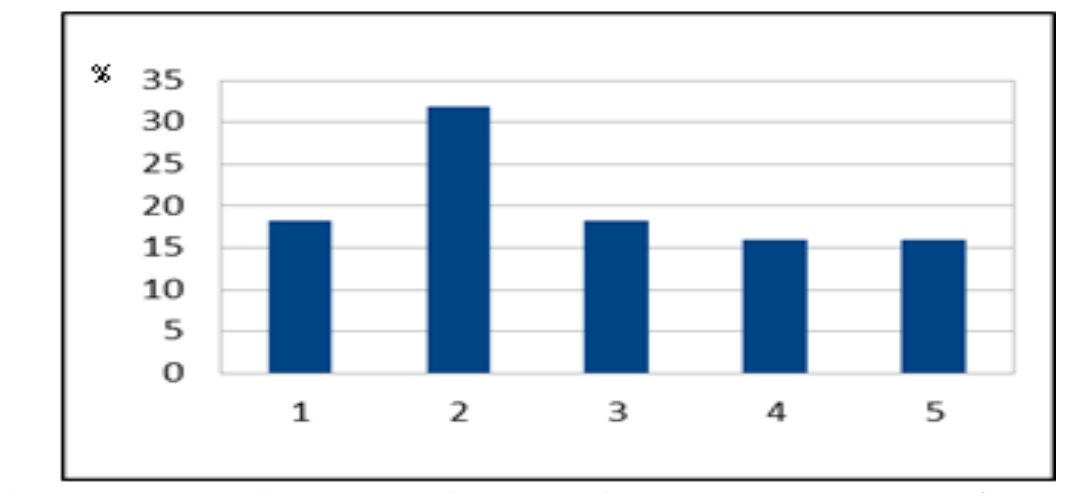

1 - Very Important, 2 - Important, 3 - Unsure, 4 - Not Too Important, 5 - Unimportant

Figure 3: Be Financially Recompensed for the Use of the Resource (\%)

The perceived quality of open education resources is a key factor that is likely to influence the adoption of these materials. Peer review is an essential process in open educational design. Thorough peer review should produce good quality products. The extent to which developers are willing to accept peer review of their work impacts directly on the sustainability of open educational initiatives. Respondents were asked how important it was to have a quality review of a resource they had created. Figure 4 indicates that slightly more than half (51\%) recognised that it was very important to have resources peer reviewed and $78 \%$ state that this was at least an important requirement.

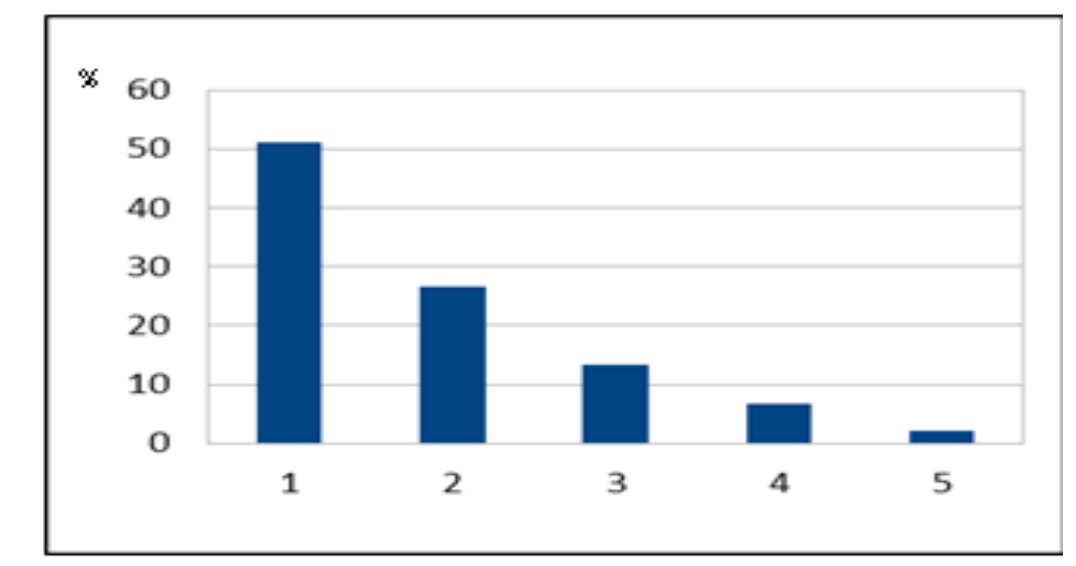

1 - Very Important, 2 - Important, 3 - Unsure, 4 - Not Too Important, 5 - Unimportant

Figure 4: Subject the Resource to Review 


\section{What Barriers do Faculty Anticipate in Terms of Engaging with OERs?}

While faculty might, with the right incentives, be inspired and ready to engage in OER development and implementation, respondents were aware of possible obstacles to such projects. The significance of these potential barriers was rated on a 5 -point Likert scale $(1=$ very significant, $5=$ insignificant). Table 3 shows the "very significant-to-significant" range of responses for each of the anticipated barriers.

Table 3: Potential Barriers to OER Development and Implementation

\begin{tabular}{|l|l|}
\hline \multicolumn{1}{|c|}{ Nature Of The Potential Barrier } & \multicolumn{1}{|c|}{$\begin{array}{c}\text { Percent Of Respondents Rating The Perceived } \\
\text { Barrier As Significant-To-Very Significant (\%) }\end{array}$} \\
\hline Lack of technical/computer skills (staff members) & 70 \\
\hline Lack of technical/computer skills (students) & 77 \\
\hline Lack of time to find and learn to use suitable OERs & 79 \\
\hline Lack of time to develop OERs & 69 \\
\hline Lack of hardware (computers and printers) & 80 \\
\hline Lack of software (programmes) & 68 \\
\hline Limited access to computers & 67 \\
\hline No/limited internet access & 72 \\
\hline $\begin{array}{l}\text { No reward system for faculty who make time and effort to } \\
\text { develop resources }\end{array}$ & 69 \\
\hline $\begin{array}{l}\text { Lack of interest from faculty in contributing to pedagogical } \\
\text { innovation }\end{array}$ & 69 \\
\hline Lack of interest from students & 56 \\
\hline No/insufficient support from university management & 43 \\
\hline Generally poor quality of available OERs in terms of usage value & \\
\hline
\end{tabular}

Table 3 is perhaps most instructive if one interprets it in the light of relative percent values. Thus the possible poor quality of available OERs appears to be respondents' least significant concern. In addition to perceived lack of interest in OERs from students, limited internet and computer access and lack of interest from faculty seem to be less problematic than a generally reported lack of time to find, use and develop these materials. It is indeed possible that the traditional demands on staff to teach, assess, research and publish leave little or no time for OER trials. This state of affairs could easily be interpreted as a lack of support from university management for institutional OER initiatives and evidently was, to a greater or lesser degree, by $80 \%$ of respondents. This is not an uncommon experience (see Section 2.5).

The impression that suggests itself is that there may be a latent affinity for students and staff to experiment with OERs but that this is not meaningfully encouraged by the university. Why this might be the case is a potentially fraught question complicated by issues such as institutional culture, attitudes to copyright and intellectual property, concerns about preserving established business models and so forth. A clear endorsement of the benefits of open education resources is the indication by $76.5 \%$ of the respondents that they would consider using these products alongside proprietary content if formal university support was made available to do so $(21.6 \%$ stated that they probably would). The mean number of hours per month that respondents were prepared to devote to developing OERs in their field/subject is 21 .

\section{CONCLUSIONS}

The potential benefits of OERs are generally well recognised. However, in spite of the obvious merits of these materials, the open education movement faces challenges which are rooted significantly, although not exclusively, in educators' notions of OERs. This paper sought to examine the attitudes Durban University of Technology faculty have towards OERs with the aim of gauging their readiness and capability to be actively involved as developers and users of these materials.

Experience and tradition are likely to inform attitudes. More than half the respondents indicated that they employ OERs and that these materials, consisting primarily of notes and exercises/quizzes and tutorials/tasks, comprised roughly a fifth of their stock of instructional aids. The vast majority of respondents rated the quality of 
OERs they had used as generally reasonable-to-good. However in spite of some, albeit relatively unsophisticated use of open educational materials, faculty appear to prefer the traditional resources of prescribed texts and content that they have authored themselves. Thus, even though respondents reported an impressive level of competence in ICT use, a requirement to access many OERs, copyright instructional materials appear to be the default options. Only a minority of respondents reported sharing the teaching aids they had produced.

The reality that faculty source and make at least limited use of OERs but are apparently not that keen to share their own materials seems a contradiction. On the one hand it suggests an awareness of the benefits of OERs but at the same time also a hesitance to test the full range and power of these materials by bringing them more boldly into the mainstream of educational practice. On the other hand the relatively low level of sharing of original content amongst faculty begs the question as to whether there exists any real institutional ethos of openness, which is fundamental to vibrant communities of OER users and developers. It stands to reason that open education cannot function optimally in a milieu in which resources are guarded, their full potential is not reviewed and trialled on an ongoing basis and again released in a virtuous cycle of free use, peer review and improvement.

Respondents were aware that the process of peer review is aimed at producing good quality resources with clear benefits. These were recognised as more suitable and flexible teaching materials, gaining access to the best possible teaching aids, reducing education costs and promoting educational research as a publicly open activity. Thus, somewhat bemusingly, the low level of sharing of resources reported amongst DUT faculty, whilst themselves making significant use of OERs, may be symptomatic of an institutional environment that does not embrace a culture of openness. A large majority of respondents indeed felt that institutional support for OER initiatives was lacking. Even though respondents indicated that they would be prepared to devote a considerable amount of time to OER projects, the generally reported lack of time to engage in these pursuits suggests that the university's core business remains sharply focussed on its usual business of teaching, assessing, research and publication.

The expectation, however, is that open education is set to disrupt the higher education landscape. It is increasingly likely to be 'business unusual'. Many of the world's top universities are currently experimenting with different business models that are capable of leveraging the true mixed (public/private) good nature of education. Potential customers are likely in future to expect quality free resources/offerings as part of an educational programme or at least to receive credit towards a qualification for free content modules. This will not easily be achieved without universities creating a framework that will foster and sustain OER user/developer communities. Such a framework should not only create space for OER projects but should also address the very human need for recognition and acknowledgement that OER collaborators have.

\section{AUTHOR INFORMATION}

A. D. van der Merwe is a senior lecturer in the Department of Economics at the Durban University of Technology's Riverside campus. He is currently researching the potential of open education resources to boost teaching and learning in local high schools and tertiary training institutions. E-mail: $\underline{\text { alexvdm@dut.ac.za }}$

\section{REFERENCES}

1. Anon. (1948). United Nations Universal Declaration of Human Rights. United Nations. Retrieved from http://www.jus.uio.no/lm/un.universal.declaration.of.human.rights.1948/26.html

2. Brooks, D. (2012, May 3). The Campus Tsunami. The New York Times. Retrieved from http://www.nytimes.com/2012/05/04/opinion/brooks-the-campus-tsunami.html? r $r=0$

3. Butcher, N. (2010). Open Educational Resources and Higher Education (Dossier) (pp. 1-28). OER Africa, SAIDE. Retrieved from http://www.col.org/SiteCollectionDocuments/OER_Open_Educational_Resources_and_Higher_Education. pdf

4. Carey, K. (2012, January 22). MIT Mints a Valuable New Form of Academic Currency. The Chronicle of Higher Education. Retrieved from http://chronicle.com/article/MIT-Mints-a-Valuable-New-Form/130410/

5. Casserly, C. M. (2007). The Economics of Open Educational Resources. Educational Technology, 47(6), $14-19$. 
6. Caswell, T., Henson, S., Jenson, M., \& Wiley, D. (2008). Open Educational Resources: Enabling universal education. International Review of Research in Open and Distance Learning, 9(1), 1-11.

7. Elias, S. F., \& Elias, J. W. (2001). Open Education and Teacher Attitudes toward Openness: The Impact on Students. Education, 99(2), 208-214.

8. Geith, C., \& Vignare, K. (2008). Access To Education With Online Learning And Open Educational Resources: Can They Close The Gap? Journal of Asynchronous Learning Networks, 12(1), 1-22.

9. Geser, G. (Ed). (2007). Open Educational Practices and Resources OLCOS Roadmap 2012. Salzburg, Austria: Salzburg Research Edumedia Research Group. Retrieved from www.olcos.org/cms/upload/docs/olcos_roadmap.pdf

10. Hodgkinson-Williams, C. (2010). Benefits and Challenges of OER for Higher Education Institutions. Presented at the Open Educational Resources (OER) Workshop for Heads of Commonwealth Universities, Cape Town, South Africa. Retrieved from http://www.col.org/SiteCollectionDocuments/OER BenefitsChallenges_presentation.pdf

11. Kanwar, A., Kodhandaraman, B., \& Umar, A. (2010). Toward Sustainable Open Education Resources: A Perspective From the Global South. The Amer. Jrnl. of Distance Education, 24, 65-80.

12. Lundvall, B.-A. (2003). The Economics Of Knowledge And Learning. Discussion paper, Aalborg University. Retrieved from http://smartech.gatech.edu/jspui/bitstream/1853/43152/1/BengtAkeLundvall_1.pdf

13. The Department of Higher Education and Training, Government of the Republic of South Africa. (2012). Green Paper For Post-School Education And Training. Green Paper, Pretoria. Retrieved from www.info.gov.za/view/DownloadFileAction?id=157779

14. Young, J. R. (2012, July 19). Inside the Coursera Contract: How an Upstart Company Might Profit From Free Courses. The Chronicle of Higher Education. Retrieved from http://chronicle.com/article/How-anUpstart-Company-Might/133065/

15. Yuan, L., Macneill, S., \& Kraan, W. (2008). Open educational resources-Opportunities and challenges for higher education. Discussion paper. Retrieved from http://wiki.cetis.ac.uk/images/6/6d/OER Briefing_Paper_CETIS_without_recommendations_with_cover_p age.pdf 
NOTES 